\title{
Can the use of methylprednisolone, vitamin C, or $\alpha$-trinositol prevent cold-induced fluid extravasation during cardiopulmonary bypass in piglets?
}

\author{
M. Farstad, MD \\ J. K. Heltne, MD, PhD \\ S. E. Rynning, $M D, P h D^{b}$ \\ H. Onarheim, MD, $\mathrm{PhD}^{\mathrm{a}}$ \\ A. Mongstad, $\mathrm{RP}^{\mathrm{b}}$ \\ F. Eliassen, $R P^{b}$ \\ P. Husby, MD, $\mathrm{PhD}^{\mathrm{a}}$
}

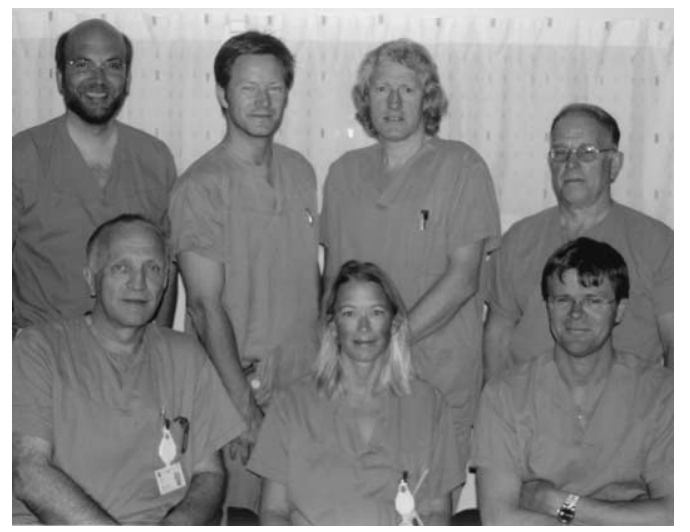

Front row, left to right, Husby, Farstad, Rynning; back row, left to right, Onarheim, Heltne, Mongstad, Eliassen.

Objective: Hypothermic cardiopulmonary bypass is associated with capillary fluid leakage, resulting in edema and occasionally organ dysfunction. Systemic inflammatory activation is considered responsible. In some studies methylprednisolone has reduced the weight gain during cardiopulmonary bypass. Vitamin $\mathrm{C}$ and $\alpha$-trinositol have been demonstrated to reduce the microvascular fluid and protein leakage in thermal injuries. We therefore tested these three agents for the reduction of cold-induced fluid extravasation during cardiopulmonary bypass.

Methods: A total of 28 piglets were randomly assigned to four groups of 7 each: control group, high-dose vitamin $\mathrm{C}$ group, methylprednisolone group, and $\alpha$-trinositol-group. After 1 hour of normothermic cardiopulmonary bypass, hypothermic cardiopulmonary bypass was initiated in all animals and continued to 90 minutes. The fluid level in the extracorporeal circuit reservoir was kept constant at the $400-\mathrm{mL}$

From the Departments of Anesthesia and Intensive Care ${ }^{\mathrm{a}}$ and Heart Disease, ${ }^{\mathrm{b}}$ University of Bergen, Haukeland University Hospital, Bergen, Norway.

Supported by the Norwegian Research Council, the Norwegian Council on Cardiovascular Diseases, the Medical Faculty of the University of Bergen, and the Laerdal Foundation for Acute Medicine. M.F. is a research fellow of the University of Bergen, Norway.

Received for publication Jan 27, 2003; revisions requested March 24, 2003; revisions received April 1, 2003; accepted for publication April 21, 2003.

Address for reprints: P. Husby, MD, PhD, Department of Anesthesia and Intensive Care, Haukeland University Hospital, N-5021 Bergen, Norway (E-mail: phus@haukeland.no).

J Thorac Cardiovasc Surg 2004;127:525-34 $0022-5223 / \$ 30.00$

Copyright () 2004 by The American Association for Thoracic Surgery

doi:10.1016/S0022-5223(03)01028-6 level and used as a fluid gauge. Fluid needs, plasma volume, changes in colloid osmotic pressure in plasma and interstitial fluid, hematocrit, and total water contents in different tissues were recorded, and the protein masses and the fluid extravasation rate were calculated.

Results: Hemodilution was about $25 \%$ after start of normothermic cardiopulmonary bypass. Cooling did not cause any further changes in hemodilution. During steadystate normothermic cardiopulmonary bypass, the fluid need in all groups was about $0.10 \mathrm{~mL} /(\mathrm{kg} \cdot \mathrm{min})$, with a 9-fold increase during the first 30 minutes of cooling $(P$ $<.001)$. This increased fluid need was due mainly to increased fluid extravasation from the intravascular to the interstitial space at a mean rate of $0.6 \mathrm{~mL} /(\mathrm{kg} \cdot \min )$ (range $0.5-0.7 \mathrm{~mL} /[\mathrm{kg} \cdot \min ] ; P<.01$ ) and was reflected by increased total water content in most tissues in all groups. The albumin and protein masses remained constant in all groups throughout the study.

Conclusion: Pretreatment with methylprednisolone, vitamin C, or $\alpha$-trinositol was unable to prevent the increased fluid extravasation rate during hypothermic cardiopulmonary bypass. These findings, together with the stability of the protein masses throughout the study, support the presence of a noninflammatory mechanism behind the cold-induced fluid leakage seen during cardiopulmonary bypass. 


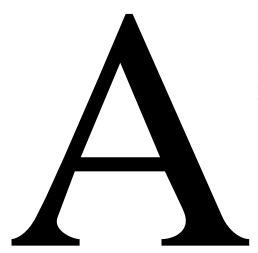

lthough most patients undergoing surgical procedures that require cardiopulmonary bypass (CPB) have few long-term adverse sequelae, the use of $\mathrm{CPB}$ continues to be associated with significant morbidity, despite the many advances made in perfusion techniques. Neonates and infants are particularly susceptible to the adverse effects of CPB, which may be related to a well-documented CPB-induced whole-body inflammatory reaction seen in adults as well as children, with endothelial cell injury, adhesion molecule up-regulation, neutrophil activation, and initiation of the coagulation cascade with a number of inflammatory mediators elevated during and after bypass. ${ }^{1-3}$ Although it is clear that a substantial inflammatory reaction is present during and after $\mathrm{CPB}$, the significance of the elevated mediators is still uncertain.

The deleterious effects of bypass-induced inflammation may be excessive total body edema caused by a capillary leak syndrome, occasionally resulting in organ dysfunction affecting especially the lung and heart. Although determination of the different inflammatory mediators is beyond the scope of this study, it is well known that different antiinflammatory strategies, including the use of glucocorticoids, have been shown to reduce the level of circulating inflammatory mediators such as interleukins 6 and 8 and tumor necrosis factor- $\alpha$ after CPB. ${ }^{4}$ Some clinical and experimental experiences have suggested that giving agents such as methylprednisolone before CPB may improve its course, leading to reduced fluid gain during CPB and shorter intensive care unit stay. ${ }^{5,6}$ In contrast, other studies have failed to find such effects, and adverse consequences have even been reported. ${ }^{7}$

We recently reported on increased fluid extravasation from the intravascular to the interstitial space during CPB. ${ }^{8,9}$ We hypothesized that administration of methylprednisolone, well known to modulate the whole-body inflammatory response syndrome, could contribute to reducing or even preventing the increased fluid extravasation rate (FER) present during normothermic and hypothermic CPB. In the same piglet model, we also tested the effects of vitamin $\mathrm{C}$ and $\alpha$-trinositol, both of which have been demonstrated to be suitable to reduce fluid gain in other inflammatory conditions and in thermal injuries. ${ }^{10,11}$

\section{Materials and Methods}

\section{Animal Handling and Anesthesia}

We studied 28 domestic pigs with an age of approximately 3 months (Norwegian landrace Norhybrid; Stend Agricultural College, Fana, Norway) divided into four groups: control group ( $\mathrm{n}=$ $7)$, methylprednisolone group $(\mathrm{n}=7)$, vitamin $\mathrm{C}$ group $(\mathrm{n}=7)$, and $\alpha$-trinositol group $(\mathrm{n}=7)$. In a separate series of animals that never went through $\mathrm{CPB}$ (non-CPB group), tissue samples were taken for determination of the total tissue water content (TTW) as a baseline control.

The animal handling was in accordance with recommendations given by The Norwegian State Commission for Laboratory Animals. Food was withdrawn 12 hours before the study. Water was provided at all times.

Anesthesia was carried out with midazolam and fentanyl infusion and isoflurane inhalation, as previously described elsewhere. ${ }^{12}$ Heart rate was measured with surface electrocardiographic electrodes. Systemic arterial pressures were monitored continuously with a catheter introduced into the right femoral artery and connected to a pressure transducer (Transpac II; Abbott Critical Care Systems, Sligo, Ireland) linked to a monitor (HP78353A monitor; Hewlett-Packard Company, Palo Alto, Calif). Central venous pressure was measured in the inferior vena cava with a catheter introduced through the femoral vein and connected by way of a pressure transducer to the same monitor.

Preparation for extracorporeal circulation was done after IV administration of heparin $(6 \mathrm{mg} / \mathrm{kg}$ body weight plus $3 \mathrm{mg} / \mathrm{kg}$ after 1 hour). An 18F aortic arch cannula (AA-018-C; Research Medical, Inc, Salt Lake City, Utah) was inserted into the ascending aorta, and a 32F single venous return cannula (TF-034-L,; Research Medical) was inserted into the right atrium and connected to standard equipment for heart surgery. This consisted of a membrane oxygenator with reservoir and integrated heat exchanger (Spiraloxy HSR-4000; Baxter Healthcare Corporation CardioVascular Group, Irvine, Calif). The CPB circuit was primed with 1000 $\mathrm{mL}$ of acetated Ringer's solution. This regularly resulted in a filling of the machine reservoir to the 400-mL level. Pump flow during CPB was set according to our clinical practice to $2.7 \mathrm{~L} /(\mathrm{min}$ $\cdot \mathrm{m})^{2}$. Flow pattern was nonpulsatile. In all groups the CPB pump head pressures were in the range of 200 to $250 \mathrm{~mm} \mathrm{Hg}$. During CPB the height difference between machine reservoir and the site of venous drainage (the right atrium) was fixed $(73 \pm 3 \mathrm{~cm})$.

All surgical procedures were normally completed within 30 min. The animals were thereafter allowed 60 minutes of stabilization before the start of CPB. Thereafter CPB was initiated and continued for 150 minutes. All animals underwent 60 minutes of normothermic $\mathrm{CPB}\left(39^{\circ} \mathrm{C}\right)$ followed by 90 minutes of hypothermic $\mathrm{CPB}$. By setting the water temperature of the $\mathrm{CPB}$ heat exchanger to $5^{\circ} \mathrm{C}$, a drop of the core temperature from $38^{\circ} \mathrm{C}$ to $28^{\circ} \mathrm{C}$ was achieved within 15 to $20 \mathrm{~min}$. Nasopharyngeal and rectal temperatures were measured continuously. At the end of each experiment, the pigs were killed with an intravenous injection of $20 \mathrm{~mL}$ saturated potassium chloride solution.

\section{Administration of the Test Drugs}

Methylprednisolone (Solu-medrol, $30 \mathrm{mg} / \mathrm{kg}$ ) was given intramuscularly 8 hours before induction of anesthesia ${ }^{13}$ and supplemented with an additional $30 \mathrm{mg} / \mathrm{kg}$ given intravenously after induction. Vitamin C, (Wörwag Pharma, Böblingen, Germany) 1000 mg, was given as an intravenous bolus injection after induction of anesthesia, followed by an intravenous infusion of $14 \mathrm{mg} /(\mathrm{kg} \cdot \mathrm{h})$ throughout the experiment. Similarly, $\alpha$-trinositol (Perstorp Pharma AB, Perstorp, Sweden) was given as an intravenous bolus injection of $120 \mathrm{mg}$ followed by an intravenous infusion of $40 \mathrm{mg} / \mathrm{h}$. 


\section{Blood Sampling and Blood Analysis}

Analyses of hemoglobin concentration, hematocrit, mean corpuscular volume, and serum albumin, serum total protein, and serum electrolyte concentrations, as well as acid-base parameters were performed on blood sampled from the arterial line. Hemoglobin concentration was analyzed with a Coulter analyzer (OSM 3 Hemoximeter; Radiometer, Copenhagen, Denmark). Hematocrit was determined with standard hematocrit tubes centrifuged at $12,000 \mathrm{rpm}$ for 10 minutes. Serum albumin and total protein concentrations were analyzed in an automatic analyzer (Technicon Chemi Systems; Bayer Corporation, Pittsburgh, Pa) by colorimetry and by the biuretic reaction, respectively.

\section{Colloid Osmotic Pressure}

Colloid osmotic pressure (COP) was measured in plasma and interstitial fluid with a colloid osmometer designed to accept sample volumes down to $5 \mu \mathrm{L} .{ }^{14}$ The semipermeable membrane had a cutoff level at 10,000 d (PM-10; Amicon Inc, Beverly, Mass), and acetated Ringer's solution was used in the reference chamber. The pressures were measured by a pressure transducer (Gould-Statham; Spectramed Inc, Lewis Center, Ohio) connected to a recorder (Easy-Graph 240; Gould Electronics Inc, Eastlake, Ohio).

\section{Sampling of Interstitial Fluid}

Sampling of subcutaneous interstitial fluid was performed with the wick technique. Multifilamentous nylon wicks (Enkalon $3 \times 3$, Enka bv Produktgroup Industriele Garens, Holland) were sewn with a straight suture needle (Acufirm 214/1, Dreieich, Germany) in lengths of 8 to $10 \mathrm{~cm}$ into thoracoabdominal skin folds. Before implantation, the wicks were soaked in acetated Ringer's solution. To prevent evaporation of fluid, the protruding ends of the wicks were covered with an adhesive plastic film (Tegaderm; 3M Inc, London, Ontario, Canada). The wicks were left in situ for 90 minutes. ${ }^{15}$ At the end of the implantation period, the wicks were pulled out swiftly and placed under mineral oil in centrifuge tubes. Wick fluid $(5-15 \mu \mathrm{L})$ was collected after centrifugation. Blood contamination of wicks was judged visually when removing each wick from the animal. Only white or light pink wicks were accepted. Wick fluid from three implantation periods (before CPB, during normothermic $\mathrm{CPB}$, and during hypothermic $\mathrm{CPB}$ was analyzed.

\section{TTW}

Immediately after the animals were killed, tissue samples (0.4-0.6 $\mathrm{g}$ in three parallel pieces) were collected from left quadriceps, abdominal skin, colon, ileum, stomach, liver, pancreas, kidney, lung, and heart (left and right ventricular myocardium), placed in preweighed open vials, bottled immediately, reweighed as soon as possible, and placed unbottled in a drying chamber at $70^{\circ} \mathrm{C}$. The vials were weighed repeatedly until a stable weight was reached. TTWs were recorded as grams of water per gram of dry weight and compared with the values obtained from the non-CPB group animals.

\section{Fluid Loss and Supplementation}

Urinary output and fluid balance were recorded half hourly. Urinary output was monitored through a suprapubic catheter.
A continuous infusion of acetated Ringer's solution $(5 \mathrm{~mL} /(\mathrm{kg}$ - h) was given as maintenance fluid. Blood loss was substituted with Ringer's solution in volumes 3 times the blood loss. Before CPB blood loss was measured by weighing the surgical sponges. During CPB blood loss into the open chest was returned by suction to circulation through the extracorporeal machine reservoir.

During CPB the level of fluid in the machine reservoir was measured continuously. Changes from the 400-mL level were recorded at 5-minute intervals. Such changes were used as an indicator of fluid loss (or gain) from the circulation to the interstitial space or changes in vascular tone. Whenever the reservoir blood level fell, acetated Ringer's solution was supplied to restore the 400-mL level. After start of hypothermic CPB fluid additions and net fluid balance were calculated on a half hourly basis and compared with the values obtained during the last half hour of normothermic CPB.

\section{Blood Volume Determination With the Carbon Monoxide Method}

Red blood cell volume was determined just before CPB by the carbon monoxide method as recently described. ${ }^{16}$ Subsequent blood and plasma volumes were calculated from determination in the changes of the hematocrit values and corrected for blood losses. To assess the real plasma volumes within the animal during $\mathrm{CPB}$, the calculated plasma volumes were corrected according to the following equation: Real volume $=$ Calculated volume Volume in CPB circuit.

\section{Albumin and Protein Mass and Albumin and Protein Extravasation}

Total intravascular albumin and protein masses (in grams) were calculated as the product of measured plasma volume (within animal, tubings, and reservoir in milliliters) and the serum albumin or protein concentrations in grams per $1000 \mathrm{~mL}$. Extravasation or intravasation of albumin and protein was calculated as the changes in the albumin and protein masses from one moment to another.

\section{Statistical Methods}

The results are presented as mean \pm SEM. All data were analyzed by means of the Graph Pad InStat (version 3.02; GraphPad Software, Inc, San Diego, Calif).

The repeated measure analysis of variance with one grouping variable was used to test the relationship of the outcome variable at different times. If a significant between-group $P$ value was found, a 1-way analysis of variance was applied, followed by the Tukey-Kramer multiple comparisons test. Further, on finding a significant within-group $P$ value a post hoc paired $t$ test was used. The level of significance was adjusted according to the number of comparisons. The 1-way analysis of variance was also used when comparing the non-CPB, control, and interventional groups. This test was followed by the Tukey-Kramer multiple comparisons test, when necessary.

\section{Results}

All study groups were comparable with respect to weight, age, and sex (Table 1). Mean arterial pressure, central venous pressure, and diuresis are presented in Table 2. All 
TABLE 1. Animal data

\begin{tabular}{lccrrr}
\hline & Control & Vitamin C & Methylprednisolone & $\boldsymbol{\alpha}$-Trinositol & Non-CPB \\
\hline Weight (kg) & $32.2 \pm 1.1$ & $33.2 \pm 0.8$ & $34.0 \pm 1.6$ & $30.3 \pm 1.6$ & $32.7 \pm 1.0$ \\
Age (d) & $91 \pm 5.3$ & $94 \pm 7.9$ & $103 \pm 11.5$ & $97 \pm 7.1$ & $95 \pm 2.3$ \\
Sex (male/female) & $6: 1$ & $7: 0$ & $7: 0$ & $5: 2$ & $11: 2$ \\
\hline
\end{tabular}

The values are presented as mean \pm SEM. The non-CPB group was used as a control group for TTW.

TABLE 2. Mean arterial pressure, central venous pressure, and diuresis in all groups during study

\begin{tabular}{|c|c|c|c|c|c|c|c|c|}
\hline \multirow[b]{2}{*}{ Parameters } & \multirow[b]{2}{*}{ Group } & \multirow{2}{*}{$\begin{array}{c}\text { Prebypass } \\
(0 \mathrm{~min})\end{array}$} & \multicolumn{3}{|c|}{ Normothermic CPB } & \multicolumn{3}{|c|}{ Hypothermic CPB } \\
\hline & & & 0 min & $30 \mathrm{~min}$ & $60 \mathrm{~min}$ & $90 \mathrm{~min}$ & $120 \mathrm{~min}$ & $150 \mathrm{~min}$ \\
\hline \multirow[t]{4}{*}{ Mean arterial pressure $(\mathrm{mm} \mathrm{Hg})$} & CT & $48 \pm 3.8$ & $50 \pm 4.1$ & $50 \pm 1.9$ & $53 \pm 2.6$ & $52 \pm 1.9$ & $55 \pm 3.2$ & $56 \pm 3.7$ \\
\hline & VC & $56 \pm 2.6$ & $49 \pm 3.3$ & $55 \pm 2.0$ & $63 \pm 4.3$ & $56 \pm 3.6$ & $66 \pm 7.2$ & $63 \pm 4.9$ \\
\hline & MP & $70 \pm 4.9$ & $59 \pm 5.4$ & $60 \pm 1.9$ & $63 \pm 4.5$ & $66 \pm 5.4$ & $78 \pm 5.0^{*} \dagger$ & $73 \pm 4.4$ \\
\hline & AT & $61 \pm 5.4$ & $48 \pm 2.2$ & $52 \pm 3.4$ & $54 \pm 4.4$ & $57 \pm 5.0$ & $59 \pm 3.9$ & $57 \pm 3.3$ \\
\hline \multirow[t]{4}{*}{ Central venous pressure $(\mathrm{mm} \mathrm{Hg})$} & CT & $6 \pm 0.8$ & $6 \pm 0.8$ & $6 \pm 0.7$ & $6 \pm 0.8$ & $6 \pm 0.8$ & $6 \pm 0.9$ & $6 \pm 0.9$ \\
\hline & VC & $7 \pm 0.4$ & $7 \pm 0.8$ & $7 \pm 0.9$ & $7 \pm 0.8$ & $7 \pm 1.0$ & $8 \pm 1.1$ & $7 \pm 1.0$ \\
\hline & MP & $7 \pm 0.8$ & $8 \pm 0.6$ & $8 \pm 0.6$ & $7 \pm 0.8$ & $7 \pm 1.1$ & $7 \pm 1.1$ & $7 \pm 1.1$ \\
\hline & AT & $6 \pm 0.6$ & $6 \pm 1.1$ & $6 \pm 0.9$ & $6 \pm 0.9$ & $6 \pm 1.1$ & $6 \pm 1.0$ & $7 \pm 0.4$ \\
\hline \multirow[t]{4}{*}{ Diuresis $(\mathrm{mL} /[\mathrm{kg} \cdot \min ])$} & CT & $0.02 \pm 0.01$ & & $0.02 \pm 0.00$ & $0.02 \pm 0.00$ & $0.11 \pm 0.06$ & $0.23 \pm 0.08$ & $0.31 \pm 0.11$ \\
\hline & VC & $0.03 \pm 0.01$ & & $0.03 \pm 0.02$ & $0.02 \pm 0.02$ & $0.06 \pm 0.05$ & $0.11 \pm 0.06$ & $0.11 \pm 0.06$ \\
\hline & MP & $0.04 \pm 0.00$ & & $0.03 \pm 0.00$ & $0.03 \pm 0.00$ & $0.13 \pm 0.06$ & $0.34 \pm 0.11 \ddagger$ & $0.47 \pm 0.13$ \\
\hline & AT & $0.02 \pm 0.01$ & & $0.03 \pm 0.01$ & $0.02 \pm 0.01$ & $0.03 \pm 0.01$ & $0.15 \pm 0.06$ & $0.10 \pm 0.03$ \\
\hline
\end{tabular}

Values are presented as mean \pm SEM. CT, Control group; VC, vitamin C group; MP, methylprednisolone group; $A T, \alpha$-trinositol group.

${ }^{*} P<.05$ compared with time 0 .

$\dagger P<.01$ compared with control value at same time.

$\ddagger P<.01$ compared with time 0 .

animals remained in stable cardiovascular condition with beating heart during CPB. Variations in acid-base parameters were similar in all groups, and the values remained within normal ranges throughout the study.

\section{Blood Chemistry}

Mean corpuscular volume and serum osmolality remained within normal range throughout the experiments in all groups (Table 3). In the methylprednisolone group, however, serum osmolality was significantly higher than in the control group throughout the experiments. The changes in hematocrit and serum albumin and total protein concentrations before and during CPB are given in Table 3.

After the start of normothermic CPB, a hemodilution on the order of $25 \%$ was present in all groups $(P<.001)$, reflected by the changes in hematocrit and serum albumin and protein concentrations as well as plasma $\mathrm{COP}\left(\mathrm{COP}_{\mathrm{p}}\right)$ values for the respective groups (Table 3 ). Hematocrit remained essentially unchanged in all groups after start of hypothermic $\mathrm{CPB}$, whereas the serum albumin and protein concentrations decreased significantly in some of the groups $(P<.05)$, as indicated in Table 3 . As demonstrated by Table 3, the serum albumin and protein concentrations of the methylprednisolone group were significantly higher than the control values throughout the study period.
Fluid Needs, Plasma Volume Changes, Net Fluid

\section{Balance, and Extravasation}

To maintain the $400-\mathrm{mL}$ level of the machine reservoir, a transient increased need for supplemental fluid was seen in all groups the first 5 to 10 minutes after the start of CPB. Thereafter the need for fluid addition to the machine reservoir decreased and stabilized at a level ranging from 0.03 to $0.18 \mathrm{~mL} /(\mathrm{kg} \cdot \mathrm{min})$ during normothermic CPB (Figure 1).

During the first 30 minutes of hypothermic CPB, the need for fluid supplementation to the machine reservoir increased significantly $(P<.001)$ to a $0.9 \mathrm{~mL} /(\mathrm{kg} \cdot \mathrm{min})$ level in all groups. No between-group differences were seen. Thereafter the fluid needs decreased but remained at levels at least 2 to 3 times that observed during normothermic CPB (Figure 1).

The plasma volume changed similarly in all groups during the experiments. After a decrease early during CPB, an increase in plasma volume to or above the initial value was seen. The changes were only statistically significant in the methylprednisolone group (Table 3). No between-group differences were observed.

Net fluid balance (total input of fluid [additions to the machine reservoir, supplementation fluid, and fluid given to correct for blood losses] minus diuresis and bleeding) increased significantly during the first 30 minutes of cooling 
TABLE 3. Blood chemistry parameters throughout study

\begin{tabular}{|c|c|c|c|c|c|c|c|}
\hline Parameters & Group & $\mathbf{n}$ & Before CPB & $60 \mathrm{~min}$ & $90 \mathrm{~min}$ & $120 \mathrm{~min}$ & $150 \mathrm{~min}$ \\
\hline \multirow[t]{4}{*}{ Mean corpuscular volume (fL) } & CT & 7 & $54.6 \pm 1.5$ & $55.3 \pm 1.7$ & $55.2 \pm 1.7$ & $54.8 \pm 1.7$ & $54.7 \pm 1.7$ \\
\hline & VC & 7 & $53.2 \pm 1.1$ & $54.1 \pm 1.2$ & $53.7 \pm 1.2$ & $53.0 \pm 1.2$ & $53.0 \pm 1.2$ \\
\hline & MP & 6 & $57.2 \pm 0.8$ & $57.9 \pm 0.8$ & $58.0 \pm 0.9$ & $57.4 \pm 0.9$ & $57.0 \pm 0.8$ \\
\hline & AT & 7 & $55.7 \pm 1.1$ & $56.8 \pm 1.2$ & $56.7 \pm 1.1$ & $56.2 \pm 1.1$ & $55.8 \pm 1.0$ \\
\hline \multirow[t]{4}{*}{ Osmolality (m0sm/kg) } & CT & 7 & $281.0 \pm 2.3$ & $281.6 \pm 2.4$ & $282.7 \pm 2.4$ & $282.1 \pm 2.4$ & $282.6 \pm 2.2$ \\
\hline & VC & 7 & $285.5 \pm 1.4$ & $291.2 \pm 1.1^{*} \dagger$ & $289.3 \pm 1.3$ & $288.7 \pm 1.1$ & $289.1 \pm 1.3$ \\
\hline & MP & 7 & $293.6 \pm 2.6 \ddagger$ & $298.7 \pm 2.4 \ddagger$ & $296.6 \pm 2.7 \ddagger$ & $295.3 \pm 2.0 \ddagger$ & $294.1 \pm 2.3 \ddagger$ \\
\hline & AT & 6 & $284.5 \pm 1.8$ & $287.3 \pm 1.2$ & $286.2 \pm 1.7$ & $283.5 \pm 1.5$ & $283.0 \pm 1.5$ \\
\hline \multirow[t]{4}{*}{ Hematocrit (\%) } & CT & 7 & $30.6 \pm 1.1$ & $23.9 \pm 0.7 \S$ & $21.4 \pm 0.6 \S$ & $21.6 \pm 0.7 \S$ & $22.1 \pm 0.7 \S$ \\
\hline & VC & 7 & $29.6 \pm 0.8$ & $26.4 \pm 0.6$ & $23.6 \pm 0.9 \S$ & $24.0 \pm 1.0 \S$ & $24.1 \pm 0.9 \S$ \\
\hline & MP & 7 & $33.4 \pm 0.8$ & $27.3 \pm 0.6 \dagger \S$ & $24.1 \pm 0.7 \S$ & $24.6 \pm 0.7 \S$ & $23.9 \pm 0.8 \S$ \\
\hline & AT & 7 & $31.0 \pm 1.0$ & $24.3 \pm 0.6 \S$ & $22.1 \pm 1.1 \S$ & $21.9 \pm 1.0 \S$ & $21.3 \pm 0.7 \S$ \\
\hline \multirow[t]{4}{*}{ Serum albumin $(\mathrm{g} / \mathrm{L})$} & CT & 7 & $27.7 \pm 1.1$ & $20.6 \pm 0.7 \S$ & $17.5 \pm 0.6 \S$ & $17.6 \pm 0.6 \S$ & $17.4 \pm 0.6 \S$ \\
\hline & VC & 7 & $29.0 \pm 0.9$ & $23.7 \pm 0.6 \S$ & $20.3 \pm 0.7 \S \|$ & $20.3 \pm 0.7 \S \|$ & $20.7 \pm 0.6 \S \emptyset$ \\
\hline & MP & 7 & $34.6 \pm 1.0 \ddagger$ & $26.8 \pm 0.8 \ddagger \S$ & $22.6 \pm 0.7+\S \|$ & $23.4 \pm 0.9+\S$ & $23.0 \pm 0.8 \mp \S$ \\
\hline & AT & 7 & $31.6 \pm 0.9$ & $23.2 \pm 0.5 \S$ & $20.0 \pm 0.6 \S$ & $19.4 \pm 0.5 \S$ & $19.2 \pm 0.6 \S$ \\
\hline \multirow[t]{4}{*}{ Serum total protein (g/L) } & CT & 7 & $43.6 \pm 1.6$ & $32.7 \pm 1.4 \S$ & $28.9 \pm 1.4 \S$ & $28.3 \pm 1.4 \S$ & $28.0 \pm 1.3 \S$ \\
\hline & VC & 7 & $47.6 \pm 2.6$ & $39.9 \pm 2.6 t^{* *}$ & $34.7 \pm 2.5 \S$ & $34.4 \pm 2.2 \S$ & $36.0 \pm 2.9+\S$ \\
\hline & MP & 7 & $52.9 \pm 1.4 \ddagger$ & $41.3 \pm 1.4 \ddagger \S$ & $35.3 \pm 1.4 \dagger \S$ & $35.9 \pm 1.4 \dagger \S$ & $35.4 \pm 1.6+\S$ \\
\hline & AT & 7 & $48.0 \pm 1.5$ & $35.6 \pm 0.5 \S$ & $30.6 \pm 1.0 \S$ & $29.7 \pm 1.2 \S \|$ & $29.1 \pm 0.9 \S \|$ \\
\hline \multirow[t]{4}{*}{ Plasma volume $(\mathrm{mL} / \mathrm{kg})$} & CT & 7 & $56.3 \pm 5.3$ & $53.5 \pm 5.7$ & $60.7 \pm 6.1$ & $61.0 \pm 7.4$ & $59.7 \pm 8.5$ \\
\hline & VC & 7 & $57.1 \pm 2.5$ & $39.7 \pm 3.3$ & $52.4 \pm 4.8$ & $52.2 \pm 5.3$ & $49.7 \pm 5.0$ \\
\hline & MP & 7 & $46.9 \pm 1.6$ & $37.5 \pm 1.9^{*}$ & $48.3 \pm 1.5$ & $46.4 \pm 1.4$ & $48.5 \pm 1.8$ \\
\hline & AT & 7 & $54.5 \pm 3.1$ & $44.4 \pm 5.2$ & $56.6 \pm 6.0$ & $57.3 \pm 5.6$ & $59.0 \pm 5.0$ \\
\hline \multirow[t]{4}{*}{$\mathrm{COP}_{\mathrm{p}}(\mathrm{mm} \mathrm{Hg})$} & CT & 7 & $14.1 \pm 0.7$ & $10.2 \pm 0.5 \S$ & $8.3 \pm 0.4 \S$ & $8.2 \pm 0.6 \S$ & $8.5 \pm 0.6 \S$ \\
\hline & VC & 7 & $15.6 \pm 0.5$ & $13.2 \pm 0.3 \ddagger^{* *}$ & $9.9 \pm 0.4 \S \emptyset$ & $10.6 \pm 0.7 \S \emptyset$ & $10.3 \pm 0.5 \S$ \\
\hline & MP & 7 & $18.4 \pm 0.6 \ddagger$ & $13.5 \pm 0.5 \ddagger \S$ & $11.2 \pm 0.5 \dagger \S$ & $11.7 \pm 0.5 \ddagger \S$ & $11.5 \pm 0.7 \dagger \S$ \\
\hline & AT & 7 & $16.0 \pm 0.3$ & $11.1 \pm 0.5 \S$ & $9.6 \pm 0.4 \S$ & $9.0 \pm 0.5 \S$ & $8.7 \pm 0.4 \S$ \\
\hline \multirow[t]{4}{*}{$\mathrm{COP}_{\mathrm{i}}(\mathrm{mm} \mathrm{Hg})$} & CT & 7 & $7.1 \pm 0.4$ & $6.5 \pm 0.4$ & & & $5.4 \pm 0.3^{*}$ \\
\hline & VC & 7 & $9.1 \pm 0.4 \uparrow$ & $8.5 \pm 0.4 \dagger$ & & & $6.6 \pm 0.5 \S \dagger \dagger$ \\
\hline & MP & 7 & $9.9 \pm 0.5 \dagger$ & $10.4 \pm 0.7 \ddagger$ & & & $8.6 \pm 0.7 \dagger$ \\
\hline & AT & 7 & $9.1 \pm 0.5$ & $7.9 \pm 0.7$ & & & $7.1 \pm 0.8$ \\
\hline \multirow[t]{4}{*}{$\mathrm{COP}_{(\mathrm{p}-\mathrm{l})}(\mathrm{mm} \mathrm{Hg})$} & CT & 7 & $8.5 \pm 0.8$ & $4.2 \pm 0.6 \S$ & & & $2.8 \pm 0.7 \S$ \\
\hline & VC & 7 & $7.2 \pm 0.7$ & $5.4 \pm 0.6$ & & & $3.9 \pm 0.6$ \\
\hline & MP & 7 & $8.8 \pm 0.5$ & $2.8 \pm 0.5 \S$ & & & $3.0 \pm 0.4 \S$ \\
\hline & AT & 7 & $7.4 \pm 0.6$ & $3.0 \pm 0.8^{* *}$ & & & $1.6 \pm 0.3 \S$ \\
\hline
\end{tabular}

Values are presented as mean \pm SEM. $C T$, Control group; VC, vitamin C group; $M P$, methylprednisolone group; $A T, \alpha$-trinositol group.

${ }^{*} P<.05$ compared with before CPB.

$\dagger P<.01$ compared with control at same time.

$\ddagger P<.001$ compared with control at same time.

$\S P<.001$ compared with before CPB.

$\| P<.05$ compared with 60 minutes (normothermic $\mathrm{CPB}$ ).

$\Uparrow P<.05$ compared with control at same time.

${ }^{* *} P<.01$ compared with before CPB.

$\mathrm{t \dagger} P<.01$ compared with 60 minutes (normothermic $\mathrm{CPB}$ ).

in all groups $(P<.001$; Figure 2$)$. Thereafter it remained at levels about twice that seen during normothermic CPB.

The calculated FER (loss of fluid from the intravascular to the interstitial space) is presented in Figure 3. The FER during hypothermic CPB increased significantly in all groups during the first 30 minutes of cooling $(P<.01)$. Thereafter FER decreased to levels about 2 to 3 times that present during normothermic CPB: $0.34 \pm 0.14,0.34 \pm$ $0.10,0.44 \pm 0.08$, and $0.51 \pm 0.11 \mathrm{~mL} /(\mathrm{kg} \cdot \mathrm{min})$ in the control, vitamin $\mathrm{C}$, methylprednisolone, and $\alpha$-trinositol groups after 60 minutes of hypothermic CPB and $0.59 \pm$
$0.09,0.45 \pm 0.05,0.37 \pm 0.05$, and $0.62 \pm 0.11 \mathrm{~mL} /(\mathrm{kg}$. $\mathrm{min}$ ) in the respective groups after 90 minutes of hypothermic CPB.

Initiation of cooling during $\mathrm{CPB}$ resulted in an increase in fluid needs, a positive net fluid balance, and an increase in FER. None of the agents tested were able to prevent or reduce these findings.

\section{COP and Albumin and Protein Masses}

Table 3 displays the $\mathrm{COP}_{\mathrm{p}}$, the $\mathrm{COP}$ of the interstitial fluid $\left(\mathrm{COP}_{\mathrm{i}}\right)$, and the colloid osmotic gradient between the intra- 

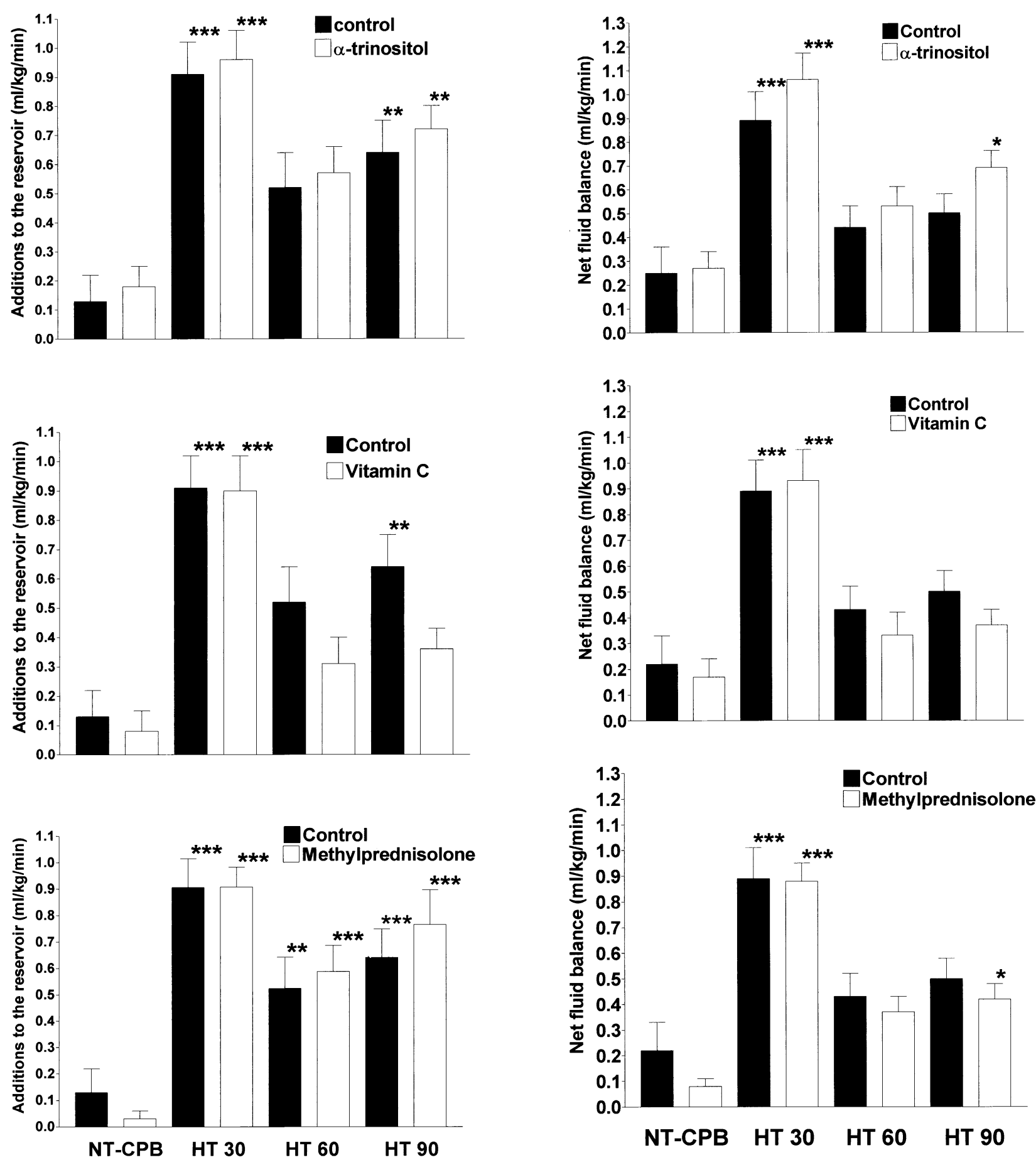

Figure 1. Fluid additions to CPB circuit reservoir during normothermic CPB (NT-CPB) and after 30 (HT 30), 60 (HT 60), and 90 (HT 90) minutes of hypothermic CPB. Double asterisk indicates $P<$ .01 ; triple asterisk indicates $P<.001$. Control is compared with each interventional group.

Figure 2. Net fluid balance during normothermic CPB (NT-CPB) and after 30 (HT 30), 60 (HT 60), and 90 (HT 90) minutes of hypothermic CPB. Asterisk indicates $P<.05$; triple asterisk indicates $P<.001$. Control is compared with each interventional group.

vascular and the interstitial fluid compartments $\left(\mathrm{COP}_{p}-\mathrm{i}\right)$. After initiation of normothermic $\mathrm{CPB}, \mathrm{COP}_{\mathrm{p}}$ decreased

significantly in all groups. $\mathrm{COP}_{\mathrm{p}}$ thereafter remained unchanged throughout the hypothermic $\mathrm{CPB}$ period. $\mathrm{COP}_{i}$ was 

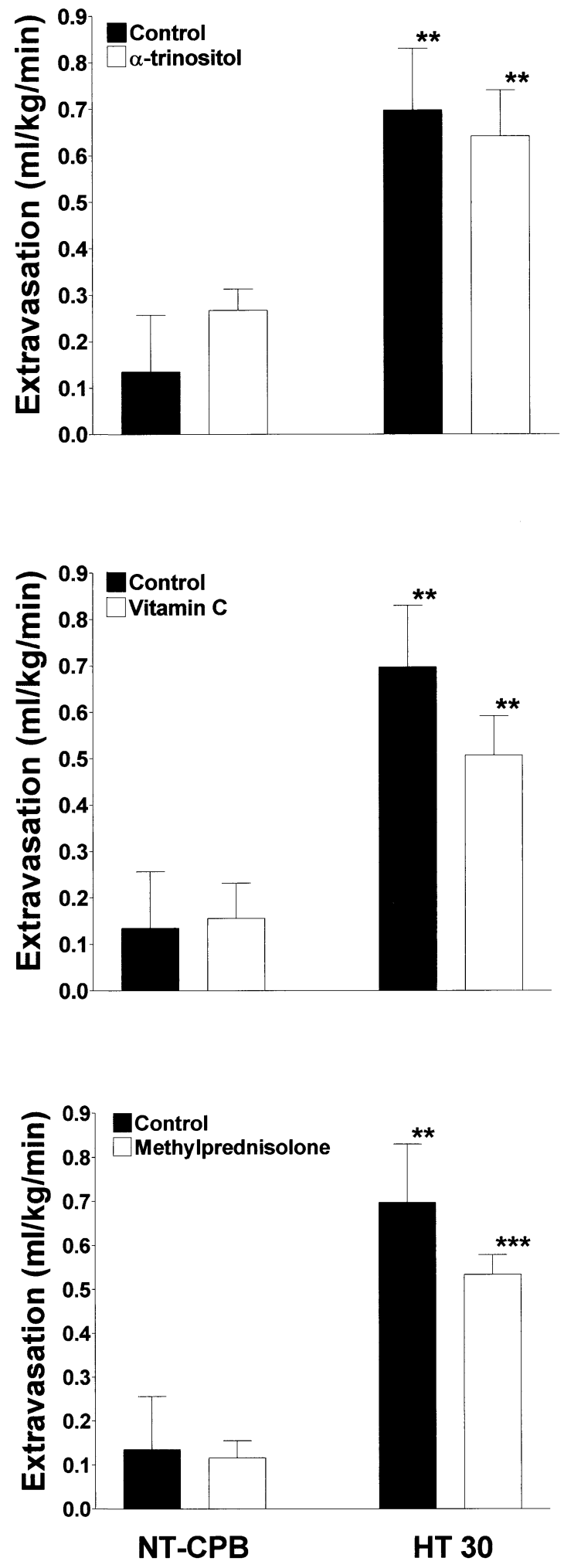

Figure 3. FER during normothermic CPB (NT-CPB) versus FER during first 30 minutes of cooling (HT 30). Double asterisk indicates $P<.01$; triple asterisk indicates $P<.001$. Control is compared with each interventional group.

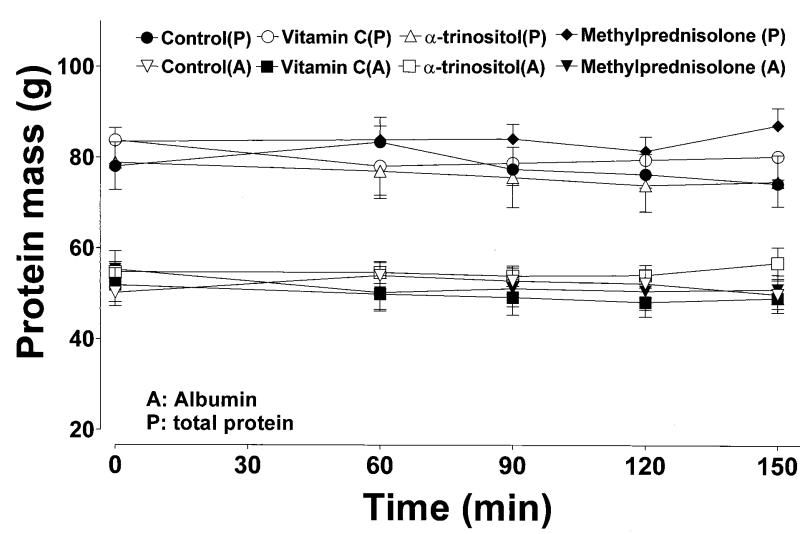

Figure 4. Albumin $(A)$ and total protein $(P)$ masses during normothermic and hypothermic CPB in control and interventional groups.

essentially unchanged through the prebypass and the normothermic CPB periods. During hypothermic CPB, $\mathrm{COP}_{\mathrm{i}}$ decreased slightly in all groups, with significant decreases in the control and vitamin $\mathrm{C}$ groups relative to the prebypass value and in the vitamin $\mathrm{C}$ group when compared with the normothermic CPB period (Table 3). The $\mathrm{COP}_{\mathrm{p}} \mathrm{-i}_{\mathrm{i}} \mathrm{de}-$ creased significantly in all groups except the vitamin $\mathrm{C}$ group after the start of $\mathrm{CPB}$, but remained essentially unchanged thereafter (Table 3 ). Some $\mathrm{COP}_{\mathrm{p}}$ values were partially (vitamin C group) or continuously (methylprednisolone group) significantly higher than the $\mathrm{COP}_{\mathrm{p}}$ values of the control group throughout the study. The calculated serum albumin and protein masses remained constant throughout the study (Figure 4).

\section{TTW}

Table 4 displays the TTWs of the different organs studied. Hypothermia increased the TTW in all organs, with significant changes in heart, lung, liver, pancreas, stomach, ileum, colon, and skeletal muscle. Neither vitamin C, $\alpha$-trinositol, nor methylprednisolone had any effect on the TTW.

\section{Discussion}

Both hemodilution and inflammation have been claimed responsible for the fluid shifts seen during CPB. Our results clearly demonstrate that the needs for fluid addition to the venous machine reservoir, the net fluid balance, and the FER increase immediately after start of cooling during CPB. The mechanisms behind the increased cold-induced microvascular permeability during CPB are still not well understood. Although few would debate the presence of a substantial inflammatory response during CPB, its involvement in the cold-induced fluid shifts seems unclear.

A "capillary leak syndrome" is characterized by generalized edema formation caused by an increase in microvas- 
TABLE 4. TTWs ( $\mathrm{g} / \mathrm{g}$ dry weight) in different tissues after hypothermic extracorporeal circulation

\begin{tabular}{|c|c|c|c|c|c|}
\hline \multirow[b]{2}{*}{ Tissue } & \multirow[b]{2}{*}{$\begin{array}{l}\text { Control } \\
(n=13)\end{array}$} & \multicolumn{4}{|c|}{ Hypothermia groups } \\
\hline & & $\begin{array}{l}\text { Hypothermia } \\
(\mathrm{n}=7)\end{array}$ & $\begin{array}{c}\text { Vitamin C } \\
(\mathrm{n}=7)\end{array}$ & $\begin{array}{c}\alpha \text {-Trinositol } \\
(\mathrm{n}=7)\end{array}$ & $\begin{array}{l}\text { Methylprednisolone } \\
\qquad(\mathrm{n}=7)\end{array}$ \\
\hline Right myocardium & $4.17 \pm 0.02$ & $4.50 \pm 0.06^{*}$ & $4.46 \pm 0.12^{*}$ & $4.61 \pm 0.08 \dagger$ & $4.52 \pm 0.11 \dagger$ \\
\hline Left myocardium & $4.00 \pm 0.04$ & $4.29 \pm 0.07^{*}$ & $4.18 \pm 0.05$ & $4.27 \pm 0.07^{*}$ & $4.15 \pm 0.09$ \\
\hline Lung & $4.16 \pm 0.07$ & $5.61 \pm 0.30 \dagger$ & $4.90 \pm 0.25 \ddagger$ & $5.39 \pm 0.22^{*}$ & $4.85 \pm 0.28 \ddagger$ \\
\hline Liver & $2.89 \pm 0.05$ & $3.28 \pm 0.06 \dagger$ & $3.22 \pm 0.06^{*}$ & $3.15 \pm 0.04^{*}$ & $3.10 \pm 0.04 \ddagger$ \\
\hline Left kidney & $4.48 \pm 0.07$ & $4.71 \pm 0.12$ & $4.57 \pm 0.05$ & $4.58 \pm 0.11$ & $4.79 \pm 0.09$ \\
\hline Right kidney & $4.56 \pm 0.08$ & $4.59 \pm 0.08$ & $4.56 \pm 0.08$ & $4.51 \pm 0.08$ & $4.84 \pm 0.11$ \\
\hline $\begin{array}{l}\text { Stomach } \\
\quad \text { (muscularis) }\end{array}$ & $4.03 \pm 0.09$ & $4.92 \pm 0.15 \dagger$ & $4.99 \pm 0.12 \dagger$ & $5.11 \pm 0.16 \dagger$ & $4.61 \pm 0.11^{*}$ \\
\hline $\begin{array}{l}\text { Stomach } \\
\text { (mucosa) }\end{array}$ & $4.41 \pm 0.08$ & $4.48 \pm 0.12$ & $4.57 \pm 0.11$ & $4.71 \pm 0.09$ & $4.41 \pm 0.14$ \\
\hline Pancreas & $3.40 \pm 0.10$ & $4.58 \pm 0.11 \dagger$ & $4.41 \pm 0.30 \dagger$ & $4.29 \pm 0.13 \dagger$ & $4.73 \pm 0.18 \dagger$ \\
\hline $\begin{array}{l}\text { Ileum } \\
\text { (muscularis) }\end{array}$ & $3.65 \pm 0.18$ & $4.26 \pm 0.24$ & $4.58 \pm 0.14 \ddagger$ & $4.72 \pm 0.08^{*}$ & $4.43 \pm 0.12 \ddagger$ \\
\hline Ileum (mucosa) & $4.72 \pm 0.05$ & $5.51 \pm 0.23 \dagger$ & $5.86 \pm 0.28 \dagger$ & $5.93 \pm 0.22 \dagger$ & $5.24 \pm 0.17 \dagger$ \\
\hline Colon & $3.85 \pm 0.19$ & $5.07 \pm 0.20 \dagger$ & $4.95 \pm 0.30^{*}$ & $5.49 \pm 0.18 \dagger$ & $4.70 \pm 0.22 \ddagger$ \\
\hline Skeletal muscle & $3.43 \pm 0.04$ & $4.00 \pm 0.06 \dagger$ & $3.89 \pm 0.09 \dagger$ & $3.97 \pm 0.05 \dagger$ & $3.94 \pm 0.08 \dagger$ \\
\hline Skin & $1.93 \pm 0.07$ & $2.28 \pm 0.20$ & $2.55 \pm 0.17^{*}$ & $2.66 \pm 0.10 \dagger$ & $2.52 \pm 0.13^{*}$ \\
\hline
\end{tabular}

Values are mean \pm SEM and compared with a control group that never went through CPB.

${ }^{*} P<.01$

$\dagger P<.001$.

$\ddagger P<.05$

cular permeability to plasma proteins. Its occurrence has been related to the presence of inflammatory cytokines and activation of the complement system. ${ }^{2}$ The existence of a capillary leak syndrome related to extracorporeal circulation has been repeatedly suggested for pediatric patients ${ }^{2,17}$ because of a decrease in plasma protein concentration soon after the onset of CPB. ${ }^{2}$ Seghaye and colleagues ${ }^{2}$ found increased microvascular leakage of proteins (molecular weight in the range $21,200-718,000 \mathrm{~d}$ ) in patients with a capillary leak syndrome, suggesting large gap formations in the microvascular basement membrane.

Many strategies and pharmacologic agents have been postulated to reduce CPB-induced inflammation and increased capillary leakage. Each of the pharmacologic interventions tested in this study has a constituency. Corticosteroids have been used for heart surgery for more than 30 years. They are potent immunosuppressive drugs with effect on several inflammatory cells. ${ }^{18}$ Thermal injury to the skin causes severe edema within hours that has been reported to be prevented by antioxidant therapy with administration of high-dose vitamin C. ${ }^{19}$ Similarly $\alpha$-trinositol has been demonstrated effective in counteracting increased vascular permeability after physical, immunologic, and agonist-induced inflammation in acute inflammatory models. ${ }^{11}$

\section{Methylprednisolone}

Corticosteroids reduce the synthesis of most cytokines. Although prebypass steroid administration may modulate the inflammatory response, resulting in improved postoperative recovery, failure ${ }^{4}$ and even adverse effects ${ }^{7}$ have also been reported. Recently Schurr and coworkers ${ }^{4}$ demonstrated that preoperative administration of methylprednisolone blunted the increase in levels of inflammatory markers such as interleukin 6, tumor necrosis factor $\alpha$, and E-selectin after $\mathrm{CPB}$ but had no measurable effect on postoperative recovery. Whereas some recent studies have demonstrated beneficial effects of steroids on the fluid homeostasis, with a significant reduction of fluid gain during $\mathrm{CPB},{ }^{6}$ other studies have failed to find such an effect. In our study methylprednisolone was given to evaluate in detail how this agent influences the microvascular fluid exchange during normothermic and hypothermic CPB. A lack of effect of methylprednisolone on FER during both normothermic and hypothermic CPB was documented by this study.

The higher albumin- and protein-concentrations, together with higher $\mathrm{COP}_{\mathrm{p}}$ and serum osmolality in the methylprednisolone group in our study could be related to an increased diuresis throughout the study period as a result of hyperglycemia and hyperglucosuria, which often follow methylprednisolone administration. This could not be confirmed, however, because serum glucose and urinary electrolytes were not analyzed.

\section{Vitamin C}

In a series of studies in animals and human beings, highdose vitamin $\mathrm{C}$ reduced early postburn microvascular leakage of fluid and proteins, ${ }^{10,19,20}$ Oxygen radicals are considered to play an important role in increased vascular 
permeability after thermal injuries. The therapeutic effect of vitamin $\mathrm{C}$ may be due to a combination of several effects and antioxidant activities on three different free radicals. Vitamin $\mathrm{C}$ terminates lipid peroxidation in the cell membrane caused by vitamin $\mathrm{E}$ radical regeneration, and it also scavenges hydroxyl and superoxide radicals. ${ }^{19}$ In addition, vitamin $\mathrm{C}$ counteracts the negative interstitial fluid hydrostatic pressure and early edema generation seen after thermal injuries. The mechanisms involved in creating the strongly negative interstitial fluid hydrostatic pressure values are not fully understood but involve changes in the structural elements of the interstitial space. ${ }^{10}$ In our study vitamin $\mathrm{C}$ administration did not affect cold-induced FER during $\mathrm{CPB}$ relative to control values.

\section{$\alpha$-Trinositol}

The use of $\alpha$-trinositol has been demonstrated to reduce edema formation and capillary albumin extravasation and to prevent the lowering of interstitial fluid hydrostatic pressure values after burn injuries, ${ }^{21}$ in different experimental inflammatory models, ${ }^{22}$ and after frostbite. ${ }^{11}$ The increased cold-induced vascular permeability associated with hypothermic CPB was, however, not influenced by the use of this agent.

\section{Hypothermia and Microvascular Fluid Exchange} During steady-state normothermic CPB, the FER remained stable, low, and on the same order as recently reported for 2 hours of stable normothermic CPB. ${ }^{8}$ At the start of cooling, however, the need for fluid addition to the machine reservoir increased abruptly in all groups. The main part of the increased fluid needs was due to fluid losses from circulation to the interstitial space, as subsequently reflected by the increases in TTW.

The mechanisms behind the cold-induced fluid extravasation are unknown but obviously not mediated by changes in the interstitial hydrostatic pressure, because $\alpha$-trinositol and vitamin $\mathrm{C}$ had no effect. The impacts of cyclic adenosine monophosphate, sodium-potassium ionic pump, and aquaporins on fluid extravasation are beyond the scope of this study, but are all topics that should be addressed in future experiments.

The lack of effect of the three tested agents and the apparent stability in both the albumin and protein masses throughout the study period may indicate that mechanisms other than inflammation are operative, increasing the capillary permeability for water and small solutes but not for proteins during cold exposure. Recently Tassani and coworkers ${ }^{23}$ presented data confirming the inflammatory response after $\mathrm{CPB}$ in patients undergoing elective coronary artery bypass grafting. In their study, contrary to expectations, the transvascular escape rate of Evans blue dye did not change from before to after CPB. Their data thus do not support the concept of increased protein leakage in the exchange vessels during bypass. ${ }^{23}$

The noninflammatory nature of the cold-induced fluid leakage is also supported by the recent study by Quing and coworkers. ${ }^{24}$ In their work moderate hypothermia $\left(28^{\circ} \mathrm{C}\right)$, in contrast to normothermia and deep hypothermia $\left(20^{\circ} \mathrm{C}\right)$, provided organ protection through its anti-inflammatory effects, including reduction in leukocyte mobilization, stimulation of interleukin 10 synthesis, and inhibition of tumor necrosis factor $\alpha$ production. The temperature level used in our study $\left(28^{\circ} \mathrm{C}\right)$ should thus act in an anti-inflammatory manner relative to normothermia. Despite this, the FER was low during normothermia and increased considerably after the start of cooling.

\section{Conclusion}

Hypothermic CPB is associated with increased fluid extravasation, which is unaffected by methylprednisolone, vitamin $\mathrm{C}$, and $\alpha$-trinositol. This finding, together with the lack of net protein extravasation during hypothermic $\mathrm{CPB}$, supports the concept of a noninflammatory mechanism behind coldinduced microvascular fluid leakage.

The Board of the Faculty of Medicine, University of Bergen, has authorized the "Locus for Circulatory Research" as an officially recognized research group within the faculty. We greatly acknowledge this support. The technical assistance of Nils Jacob Andersson, Lill Andreassen, and Cato Johnsen is greatly appreciated.

\section{References}

1. Brix-Christensen V. The systemic inflammatory response after cardiac surgery with cardiopulmonary bypass in children. Acta Anaesthesiol Scand. 2001;45:671-9.

2. Seghaye MC, Grabitz RG, Duchateau J, Busse S, Dabritz S, Koch D, et al. Inflammatory reaction and capillary leak syndrome related to cardiopulmonary bypass in neonates undergoing cardiac operations. J Thorac Cardiovasc Surg. 1996;112:687-97.

3. Tarnok A, Hambsch J, Emmrich F, Sack U, van Son J, Bellinghausen $\mathrm{W}$, et al. Complement activation, cytokines and adhesion molecules in children undergoing cardiac surgery with or without cardiopulmonary bypass. Pediatr Cardiol. 1999;20:113-25.

4. Schurr UP, Zünd G, Hoerstrup SP, Grünenfelder J, Maly FE, Fogt PR, et al. Pre-operative administration of steroids: influence on adhesion molecules and cytokines after cardiopulmonary bypass. Ann Thorac Surg. 2001;72:1316-20.

5. Jansen NJ, van Oeveren W, van den Broek L, Oudemans-van Straaten HM, Stoutenbeek CP, Joen MC, et al. Inhibition by dexamethasone of the reperfusion phenomena in cardiopulmonary bypass. J Thorac Cardiovasc Surg. 1991;102:515-25.

6. Toft P, Christiansen K, Tønnesen E, Nielsen CH, Lillevang S. Effect of methyl-prednisolone on the oxidative burst activity, adhesion molecules and clinical outcome following open heart surgery. Scand Cardiovasc J. 1997;31:283-8.

7. Chaney MA, Durazo-Arvizu RA, Nikolov MP, Blakeman BP, Bakhos M. Methyl-prednisolone does not benefit patients undergoing coronary artery bypass grafting and early tracheal extubation. J Thorac Cardiovasc Surg. 2001;121:561-9.

8. Heltne JK, Koller ME, Lund T, Farstad M, Rynning SE, Bert JL, et al. Studies on fluids extravasation related to induced hypothermia during cardiopulmonary bypass in piglets. Acta Anaesthesiol Scand. 2001;45: 720-8. 
9. Farstad M, Heltne JK, Rynning SE, Lund T, Mongstad A, Eliassen F, et al. Fluid extravasation during cardiopulmonary bypass in piglets. Effects of hypothermia and different cooling protocols. Acta Anaesthesiol Scand. 2003;47:397-406.

10. Tanaka H, Lund T, Wiig H, Reed RK, Yukioka T, Matsuda H, et al. High dose vitamin $\mathrm{C}$ counteracts the negative interstitial fluid hydrostatic pressure and early edema generation in thermally injured rats. Burns. 1999;25:569-74.

11. Berg A, Aas P, Gustafsson T, Reed RK. Effect of $\alpha$-trinositol on interstitial fluid pressure, oedema generation and albumin extravasation in experimental frostbite in the rat. J Pharmacol. 1999;126:136774.

12. Husby P, Heltne JK, Koller ME, Birkeland S, Westby J, Fosse R, et al. Midazolam-fentanyl-isoflurane anaesthesia is suitable for haemodynamic and fluid balance studies in pigs. Lab Anim. 1998;32:316-23.

13. Lodge AJ, Chai PJ, Daggett CW, Ungerleider RM, Jaggers J. Methylprednisolone reduces the inflammatory response to cardiopulmonary bypass in neonatal piglets: timing of dose is important. J Thorac Cardiovasc Surg. 1999;117:515-22.

14. Aukland K, Johnsen HM. A colloid osmometer for small fluid samples. Acta Physiol Scand. 1974;90:485-90.

15. Heltne JK, Husby P, Koller ME, Lund T. Sampling of interstitial fluid and measurement of colloid osmotic pressure (COPi) in pigs: evaluation of the wick method. Lab Anim. 1998;32:439-45.

16. Burge CM, Skinner SL. Determination of hemoglobin mass and blood volume with CO: evaluation and application of a method. $J \mathrm{Appl}$ Physiol. 1995;79:623-31.

17. Finn A, Naik S, Klein N, Levinsky RJ, Strobel S, Elliot M. Interleu- kin-8 release and neutrophile degranulation after pediatric cardiopulmonary bypass. J Thorac Cardiovasc Surg. 1993;195:234-41.

18. Rumalla V, Calvano SE, Spotnitz AJ, Krause TJ, Lin E, Lowry SF. The effects of glucocorticoid therapy on inflammatory responses to coronary artery bypass graft surgery. Arch Surg. 2001;136:1039-44.

19. Sakurai M, Tanaka H, Matsuda T, Goya T, Shimazaki S, Matsuda H. Reduced resuscitation fluid volume for second-degree experimental burns with delayed initiation of vitamin C therapy. J Surg Res. 1997; 73:24-7.

20. Tanaka H, Matsuda T, Miyagantani Y, Yukioka T, Matsuda H, Shimazaki S. Reduction of resuscitation fluid volumes in severely burned patients using ascorbic acid administration. Arch Surg. 2000; 135:326-31.

21. Lund T, Reed RK. Alpha-trinositol inhibits edema generation and albumin extravasation in thermally injured skin. J Trauma. 1994;36: 761-5.

22. Woie K, Reed RK. Neurogenic inflammation and lowering of interstitial fluid pressure in rat trachea is inhibited by alpha-trinositol. Am J Respir Crit Care Med. 1994;150:924-8.

23. Tassani P, Schad H, Winkler C, Bernhard A, Ettner U, Braun SL, et al. Capillary leak syndrome after cardiopulmonary bypass in elective, uncomplicated coronary artery bypass grafting operations: does it exist? J Thorac Cardiovasc Surg. 2002;123:735-41.

24. Qing M, Vazquez-Jimenez JF, Klosterhalfen B, Sigler M, Schumacher $\mathrm{K}$, Duchateau J, et al. Influence of temperature during cardiopulmonary bypass on leukocyte activation, cytokine balance, and postoperative organ damage. Shock. 2001;15:372-7. 